\title{
DESINSERCIÓN TARSAL LATERAL BILATERAL IDIOPÁTICA
}

\section{IDIOPATHIC LOSS OF LATERAL TARSAL SUSPENSION}

\author{
TROYANO J ${ }^{1}$, MARTÍN E ${ }^{2}$, GENOL-SAAVEDRA I I ${ }^{1}$, GARCÍA-SÁNCHEZ J ${ }^{3}$
}

\section{RESUMEN}

Caso clínico: Varón de 53 años, que presentaba ausencia de tarso en tercio externo del párpado inferior de ambos ojos. Se realizó cantoplastia lateral, con buen resultado postoperatorio.

Discusión: La dehiscencia de la unión del tarso inferior con el canto lateral sin causa conocida es un hallazgo muy infrecuente y que apenas tiene reflejo en la literatura. Están descritos dos casos de elastólisis de los párpados que asociaban ausencia de la suspensión tarsal lateral, pero ambos presentaban atrofia de la piel palpebral con alteración del componente elástico de la piel, confirmada histológicamente, mientras que en este caso la piel era normal.

Palabras clave: Cantoplastia, cantopexia, elastólisis, tira tarsal, cutis laxa.

\begin{abstract}
Case: A 53-year-old man who showed a loss of tarsal suspension in the lateral third of both lower eyelids underwent lateral canthoplasty with a good post-operative result.

Discussion: Disinsertion of the union of the inferior tarsus with the lateral canthus, of unknown cause, is a very uncommon finding that has almost never been reported in the world literature. There are two cases described of eyelid elastolysis with loss of lateral tarsal suspension, as in our case, but both showed eyelid skin atrophy and had histopathologic confirmation. Our case did not have skin atrophy (Arch Soc Esp Oftalmol 2007; 82: 369-372).
\end{abstract}

Key words: Canthoplasty, canthopexy, elastolysis, tarsal strip, cutis laxa.

\section{INTRODUCCIÓN}

Se presenta un caso de desinserción del tarso del párpado inferior de ambos ojos a nivel del ligamento cantal lateral. Se trata de una circunstancia relativamente frecuente tras determinadas cirugías palpebrales, como la tira tarsal. Sin embargo, en este caso sobrevino de manera idiopática, y de forma bilateral.

\section{CASO CLÍNICO}

Varón de 53 años de edad, asintomático, sin antecedentes personales de interés, que consulta por pérdida de pestañas en el tercio externo de ambos párpados inferiores de meses de evolución. No refiere traumatismos, cirugías, ni frotamiento crónico de los ojos. En la exploración se apreciaba ausencia de tarso en el tercio externo de ambos párpados inferiores,

\footnotetext{
Recibido: 22/6/06. Aceptado: 18/5/07.

Departamento de Oculoplastia. Hospital Clínico San Carlos. Madrid. España.

1 Licenciado en Medicina.

2 Licenciado en Medicina. Hospital de Fuenlabrada. Madrid.

3 Doctor en Medicina. Universidad Complutense de Madrid.

Correspondencia:

Juan Antonio Troyano Rivas

C/. Agustín Durán, $10,1 .^{\circ} \mathrm{D}$

28028 Madrid

España

E-mail: jtroyanorivas@hotmail.com
} 
quedando el borde libre palpebral unido al canto por un puente de piel muy fina (fig. 1). Presentaba también descenso de ambos párpados inferiores y blefaroptosis leve, no constatadas por el paciente. A petición del paciente se intervino quirúrgicamente, realizándose cantoplastia lateral con cantopexia para la corrección de la desinserción tarsal. El estudio anatomopatológico de la piel adyacente no aportó datos de interés. El postoperatorio cursó favorablemente, mejorando el descenso del párpado inferior y el contorno palpebral (fig. 2). Se le propuso a continuación cirugía de la ptosis, que el paciente rehusó.

\section{DISCUSIÓN}

La configuración de la hendidura palpebral es mantenida por los tendones cantales medial y lateral, los cuales se insertan en las placas tarsales (1). También contribuyen a dicha hendidura los músculos retractores de los párpados y el orbicular. Así, en condiciones fisiológicas, se obtiene la característica forma almendrada del contorno palpebral.

El paciente presentaba la pérdida del contorno angulado del canto lateral, con un aspecto más romo y redondeado, ausencia de pestañas en la zona de la desinserción, ya que el borde libre estaba formado a expensas de piel y tejido subcutáneo del canto, y un descenso del párpado inferior, que nosotros atribuimos al efecto del músculo retractor del párpado inferior, que carecía de la oposición de la necesaria tensión palpebral horizontal.

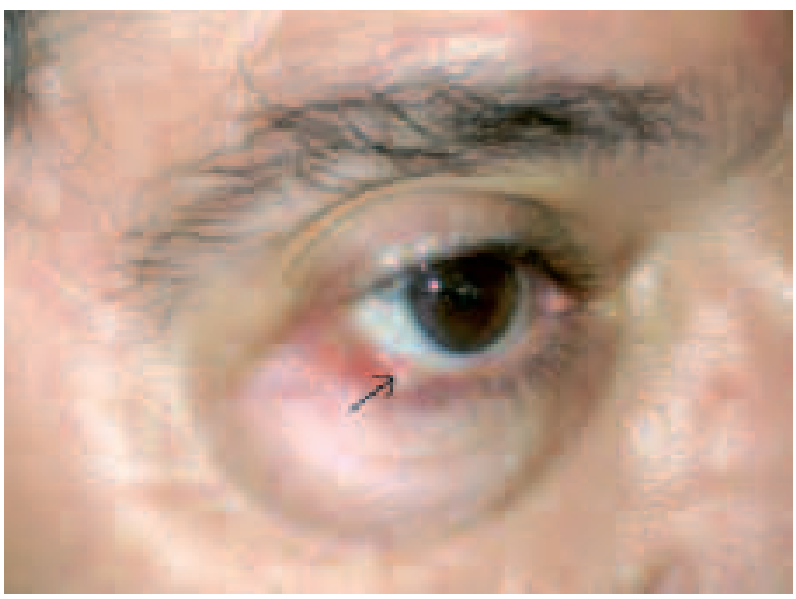

Fig. 1: Vista lateral preoperatoria. La flecha señala el límite del tarso desinsertado. Puede apreciarse el fino puente cutáneo que une el párpado inferior con el superior.

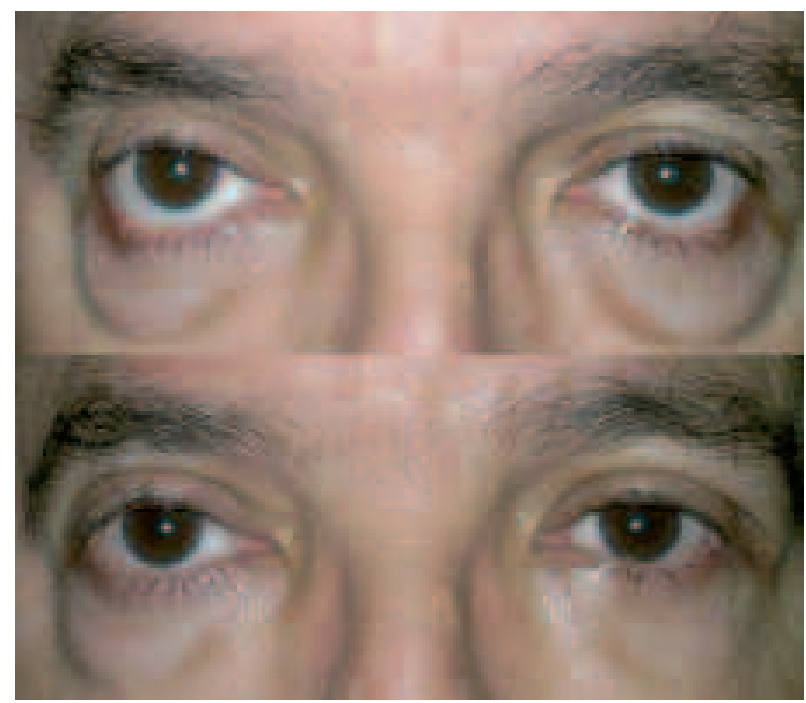

Fig. 2: Comparación pre y postoperatoria. Ha mejorado el descenso del párpado inferior y el contorno del canto lateral.

La desinserción de la unión del tarso inferior con el canto lateral sin causa conocida es un hallazgo muy infrecuente y que apenas tiene reflejo en la literatura. Están descritos dos casos de cutis laxa con afectación palpebral que asociaban ausencia de la suspensión tarsal lateral (2). Presentaban también ptosis y atrofia de la piel palpebral. Esta rara enfermedad produce una afectación del tejido elástico de la piel, denominada elastólisis, caracterizada por la pérdida selectiva de fibras elásticas en la dermis media. Puede ser congénita o adquirida, y localizada o difusa. La piel ofrece un aspecto de envejecimiento prematuro, con formación de arrugas y pliegues (3). A nivel palpebral puede cursar con dermatochalasis, atrofia cutánea y ptosis aponeurótica. El diagnóstico se obtiene a través de una biopsia cutánea de la zona afectada. Sin embargo, en nuestro caso no se apreciaba atrofia cutánea, y el estudio anatomopatológico no ofreció ninguna alteración del componente elástico de la piel.

La insuficiente laxitud del párpado inferior no permitía realizar una técnica de tira tarsal convencional, ya que para suturarla al reborde orbitario lateral hubiera sido necesario realizar un colgajo de periostio. Por ello, se prefirió reformar el canto lateral uniendo el extremo lateral del tarso inferior a la rama superior del tendón cantal lateral. A continuación se realizó una cantopexia para evitar un estrechamiento de la hendidura palpebral horizontal. Realizando una pequeña incisión en el pliegue cutá- 
neo del párpado superior, se disecaron los tejidos hasta aislar el tendón cantal lateral, el cual se suturó al periostio del reborde orbitario lateral, de forma similar a como se realiza en ocasiones en la blefaroplastia cosmética para elevar el canto (4).

Como conclusión, destacar la importancia del estudio anatomopatológico en casos similares, para descartar enfermedades cutáneas asociadas, como ha quedado reflejado anteriormente.

Asimismo, destacar la técnica empleada como una alternativa válida a la tira tarsal en casos como éste, en el que la realización de la misma sin procedimientos adicionales no es posible.

\section{BIBLIOGRAFÍA}

1. Kersten RC. Basic and clinical science course. Section 7: Orbit, Eyelids and Lacrimal System. San Francisco: American Academy of Ophthalmology; 2004; 135-146.

2. Emesz M, Wohlfart C, Schaeppi H, Kiesler J, ThallerAntlanger H. Elastolysis of the eyelids. A rare cause of ptosis. Ophthalmologe 2004; 101: 509-513.

3. Riveros CJ, Gavilan MF, Franca LF, Sotto MN, Takahashi MD. Acquired localized cutis laxa confined to the face: case report and review of the literature. Int J Dermatol 2004; 43: 931-935.

4. Shorr N, Goldberg RA, Eshaghian B, Cook T. Lateral canthoplasty. Ophthal Plast Reconstr Surg 2003; 19: 345352. 